\title{
Neural network-based Load Balancing and Reactive Power Control by Static VAR Compensator
}

\author{
Ismail K. Said and Marouf Pirouti
}

\begin{abstract}
- unbalanced loads in three phase systems produce undesired negative and zero sequence currents. Negative sequence currents will cause excessive heating of electrical machines, saturation of transformers, ripple in rectifiers or even instability problems of generators. Zero sequence currents cause not only excessive power losses in neutral lines but also protection and interference problems. To achieve a balanced operation for unbalanced AC system and improve power transfer capability, reactive compensation is used. This study use Artificial Neural Network (ANN)deals with an active scheme aiming to attenuate the negative sequence component of the line currents associated with an unbalanced three phase load. The system also assures a unity power factor at the load bus. The proposed structure uses a $\mathrm{Y}$-connected capacitor bank and _-connected thyristor reactor which is controlled by ANN, So that, the amount of reactive power is being controlled. Three different networks are learned by both real and imaginary part for three phase load currents $(I x, I y, I z)$. Hundreds of unbalanced cases in a $33(\mathrm{KV})$ system are simulated for this purpose. Study show that ANN-based reactive power compensation is completely suitable for an on-line load balancing and reactive power compensation in the system by measuring both real and imaginary part of three phase load currents and processing them by ANN.
\end{abstract}

Index Terms- ANN, Load balancing, Static VAR compensation

\section{INTRODUCTION}

Reactive power requirements of industrial loads such as electric arc furnaces, rolling mills, traction loads, arc welders, etc. are often unbalanced and could vary in a wide range within short period of time. These loads lead to unbalanced system voltages and fluctuations in the supply voltage causing many undesirable effects such as malfunction of protective relays and sensitive loads, incandescent lam flicker, and television picture distortion. Generally, the heavy loads which create these problems are located in industrial plants and supplied from on terminal network. Therefore they can be effectively compensated by shunt compensator connected at supply point of the industrial facility [1]

The recent tendency of load compensation theory is the transformation of an arbitrary ungrounded unbalanced linear load into a balanced three-phase load without changing the

Ismail K. Said is with the Electrical Department of Salahaddin University, Erbil, Iraq

Marouf Pirouti is with the Electrical Department of Salahaddin university, Erbil,Kurdistan region, Iraq, Email::m.pirouti@gmail.com,

Tel:00964-7504716749 real power exchange between loads and source, but by appropriate modification of reactive load power in each phase. Load compensation involves two separable acts; load balancing and Power factor correction. Both of them can be carried out together or separately. Modification of the reactive power of the phases can be done by connecting variable reactive source in the shunt with load element.

Despite the emergence of modern device such as STATCOMs, Static VAR Compensator (SVSc) are still popularly used in modern power distribution systems for load balancing and power factor correction due its lower cost [2].

A Static VAR Compensator generally consists of a Thyristor Controlled Reactor (TCR) and a Thyristor Switched Capacitor (TSC) and compensates loads through generation or absorption of reactive power. The operation of thyristor-controlled reactors at appropriate conduction angles can be advantageously used to meet the unbalanced and varying reactive power demand in a system [1-5].

In this study Thyristor Controlled Reactor -Fixed Capacitor (TCR-FC) is used and ANN capability in pattern recognition is applied to control of reactive power by controlling of firing angle of thyristors. Appropriate firing angles for each pair of thyristors $(\alpha \mathrm{T} 1, \alpha \mathrm{T} 2, \alpha \mathrm{T} 3)$ are predicted by three different ANNs for any unbalanced condition in the system.

\section{STATIC VAR COMPENSATOR (TCR-FC TYPE)}

The term static VAR system has been adopted to apply to a number of static VAR compensation devices for use in shunt reactive control. These devices consist of shunt connected, static reactive elements (linear or nonlinear reactor and capacitor) configured into a VAR compensating system, and their distinction is that the shunt reactive power flowing in these devices is controllable over some rated range of VARs. The basic system consists of parallel combination of fixed capacitors and thyristor switch by an angle $\alpha$, in each half cycle ( $\alpha$ increased from 900 to 1800 ) the technique of controlling the conduction intervals of the thyristor switch, generate harmonic current components [6]. Fast response and the capability of balance load make the fixed capacitor, thyristor controlled inductor particularly advantageous for compensating those loads which present rapidly at various unbalanced conditions. In this study capability of ANN is used to recognize unbalance conditions and to provide proper firing angle as quickly as possible for thyristors which provide reactive power to balance the system. FC-TCR is 
shown in Fig.1.

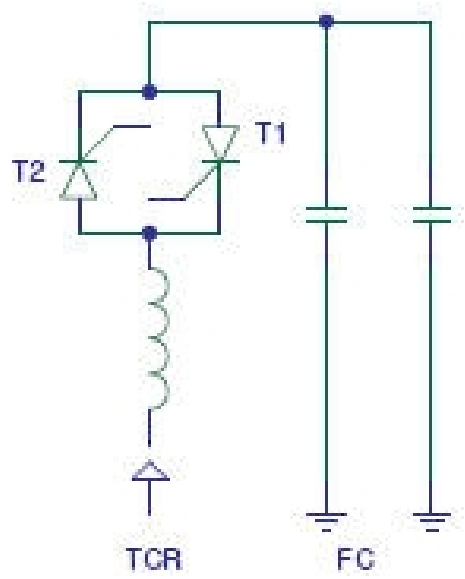

Fig.1 Fixed capacitor, thyristor-controlled inductor type

\section{ARTIFICILAL NEURAL NETWORKS}

Artificial neural networks have been widely used in the power industry in fault classification, protection, fault diagnosis, relaying schemes, load forecasting and power generation. At present most ANNs are built upon the environment of real numbers.

However it is well known that in computations related to electric power systems, such as load flow analysis and fault level estimation, complex numbers are extensively involved. The reactive power drawn from a substation, the impedance, bus bar voltages and currents are all expressed in complex numbers. But ANNs are able to deal with complex numbers by treating the real parts and imaginary parts independently. ANNs have been proved to be capable of learning from raw data. They can be used to identify relations within raw data not explicitly given or even known by human experts and there is no need to assume any linear relationship between data. ANNs represent the promising new generation of information processing networks [7].

ANNs can supplement the enormous processing power of the digital computer with the ability to make sensible decision and to learn by ordinary experience. ANNs have widely been used in electric power engineering. For energy management, load flow and optimum power flow problems are solved by ANNs to estimate bus bar voltages. ANNs can perform the task of associative memory. Since information is stored in the connections and it is distributed throughout, the network can functions as a memory. This memory can work even the presence of certain level of internal noise. ANNs are somewhat fault tolerant in the sense that information is not lost even if some connection are snapped or some units are not functioning. It can deal with data that are not only noisy, but also fuzzy, inconsistent due to associative and distributed nature. They have ability to approximate functions and automatic similarity based generalization. ANNs are distinguished based on the signal flow direction and is classified into, feed forward network and feed back network. A feed forward network is a network in which signal propagate in only one direction from an input stage through intermediate neurons to an output stage. It has no memory since output solely depends on the input. A feed back network is a network in which signal propagate from the output of any neuron to the input of any neuron. What is fed back is usually the error in the output modified appropriately according to the requirement needed. Both these models will have the three or subgroups of processing elements via, input layer, hidden layer, and output layer.

In this study multi layer feed forward network with ML back propagation training algorithm is used [8].

\section{MATHEMATICS MODELING AND SIMULATION}

In this study a three-phase $33 \mathrm{KV}$ system as shown in Fig.2, is considered. The substation is assumed to be a constant balanced voltage source and the three distribution line impedances are equal. The unbalance of the single phase loads in the system will cause an asymmetry of the line currents, and consequently unequal voltage drops on the line distribution lines. In these conditions the load bus voltages will become unbalanced. In order to improve the load power factor and to balance the line currents a fast action system is connected to the load bus. It consists of a star connected capacitor bank (Y-CCB) and a delta connected TCR bank $(\triangle$-TCR). The thyristors in the TCR are driven to provide the necessary amount of reactive power to each phase. From Fig.2, we have

- $\boldsymbol{I}_{12,}, \boldsymbol{I}_{23}, \boldsymbol{I}_{31}$ the complex values of the fundamental currents in the TCR branches.

- $\boldsymbol{I}_{a s}, \boldsymbol{I}_{b s}, \boldsymbol{I}_{c s}$ the complex values of the line currents (supply currents)

- $\boldsymbol{I}_{I c}, \boldsymbol{I}_{2 c}, \boldsymbol{I}_{3 c}$ the complex values of the currents in the capacitors.

- $\boldsymbol{I}_{x}, \boldsymbol{I}_{\boldsymbol{y}}, \boldsymbol{I}_{z}$ the complex values of the unbalanced load currents.

The load currents are:

$$
\left.\begin{array}{l}
I_{x}=I_{x l} \\
I_{y}=h^{2} * I_{y l} \\
I_{z}=h^{*} I_{z l}
\end{array}\right\} \text {---- (1) }
$$

The currents through the Y-CCB branches are balanced, which consists only reactive component and for phase (a) can be expressed as

$$
I_{c}=V_{a} / X_{c}^{----(2)}
$$

The values of the currents that must flow in the $\Delta$-TCR branches, in order to obtain the desired effects are:

$$
\left.\begin{array}{l}
I_{12}=\frac{1}{\sqrt{3}}\left[I_{c}+\operatorname{imag}\left(I_{x l}\right)+\operatorname{imag}\left(I_{y l}\right)-\operatorname{imag}\left(I_{z l}\right)\right] \\
I_{23}=\frac{1}{\sqrt{3}}\left[I_{c}-\operatorname{imag}\left(I_{x l}\right)+\operatorname{imag}\left(I_{y l}\right)+\operatorname{imag}\left(I_{z l}\right)\right] \\
I_{31}=\frac{1}{\sqrt{3}}\left[I_{c}+\operatorname{imag}\left(I_{x l}\right)-\operatorname{imag}\left(I_{y l}\right)+\operatorname{imag}\left(I_{z l}\right)\right]
\end{array}\right\}
$$

The instantaneous value of the current through one leg of the $\Delta$-TCR bank is the sum of forced and natural responses [9]:

$$
i=\sqrt{2} \frac{V}{\omega^{*} L}\left[\sin \left(w t-\frac{\pi}{2}\right)-\sin \left(\alpha-\frac{\pi}{2}\right)\right]--(4)
$$


Where $\frac{\pi}{2}<\alpha<\pi$

In order to calculate the values of the firing angle, we must calculate the ratio of $\mathrm{I}_{\mathrm{RMS}} / \mathrm{I}^{*}{ }_{\mathrm{RMS}}$ Table.1, where $\mathrm{I}_{\mathrm{RMS}}$ represents the required RMS value of the current through TCR and $\mathrm{I}^{*}$ RMS is the maximum value of the TCR's current $(\alpha=\pi / 2)$

TABLE I

\begin{tabular}{|c|c|c|c|}
\hline $\begin{array}{c}\mathbf{I}_{\mathbf{R M S}} \mathbf{I}_{\mathbf{R M}}{ }_{\mathbf{R}} \\
\mathbf{S}\end{array}$ & $\alpha(\mathbf{R A D})$ & $\mathbf{I}_{\mathbf{R M S}} / \mathbf{I}_{\mathbf{R M}}{ }_{\mathbf{S}}$ & $\alpha(\mathbf{R A D})$ \\
\hline 0 & 3.14 & 0.55 & 1.956 \\
\hline 0.1 & 2.708 & 0.6 & 1.909 \\
\hline 0.15 & 2.567 & 0.65 & 1.863 \\
\hline 0.2 & 2.376 & 0.7 & 1.818 \\
\hline 0.25 & 2.3 & 0.75 & 1.775 \\
\hline 0.3 & 2.232 & 0.8 & 1.733 \\
\hline 0.35 & 2.17 & 0.85 & 1.691 \\
\hline 0.4 & 2.112 & 0.9 & 1.65 \\
\hline 0.45 & 2.058 & 0.95 & 1.61 \\
\hline 0.5 & 2.006 & 0.99 & 1.579 \\
\hline
\end{tabular}

Since the currents in the bank are in quadrate lagging the line voltages, they have the expressions:

$$
\left.\begin{array}{l}
\underline{I}_{12}=-h * I_{12} \\
\underline{I}_{23}=-I_{23} \\
\underline{I}_{31}=-h^{2} * I_{31}
\end{array}\right\}
$$

Using first Kerchief's law, the supply currents will be:

$$
\left.\begin{array}{l}
I_{a s}=I_{c}+\underline{I}_{12}-\underline{I}_{31}+I_{x} \\
I_{b s}=h^{2} * I_{c}+\underline{I}_{23}-\underline{I}_{12}+I_{y} \\
I_{c s}=h * I_{c}+\underline{I}_{31}-\underline{I}_{23}+I_{z}
\end{array}\right\}
$$

In this paper, based above relations the value of firing angle of TCR' Thyristors (one branch) as function of $\mathrm{I}_{\mathrm{RMS}}$ is calculated. In order to generalize, these values are calculated as a function of $\mathrm{I}_{\mathrm{RMS}} / \mathrm{I}^{*}{ }_{\text {RMS }}$ ratio Table.1, where $\mathrm{I}_{\mathrm{RMS}}$ represents the required RMS value of the current through TCR and $\mathrm{I}^{*}{ }_{\mathrm{RMS}}$ is the maximum value of the TCR's RMS current at $(\alpha=\pi / 2)$. For providing data in ANN application, based above mathematical background a program in MATLAB is written for this purpose [10]. Hundreds of unbalanced conditions by using this program are simulated and appropriate $\alpha$ is obtained.

\section{RESULT}

Multilayer feed forward networks were chosen to process the prepared input data. In this study 749 unbalanced cases were simulated and appropriated firing angle for each pair of thyristors $(T 1, T 2, T 3)$ was obtained. 66 percent of all data was used for training and others were applied for testing the networks. Three multilayer feed forward networks with proposed scheme as shown in Fig.2. are considered for this propose. Both real and Img parts of three phase load current $I x, I y$ and $I z$ after normalization were fed to neural networks. The networks' architectures were decided empirically by using trail and error method for choosing best ANN structure which is involved to training and testing different number of networks. Unfortunately, it is difficult to know beforehand how large a network should be for a specific application. If a larger network is used the more complex functions of the network can be created and if small enough networks are selected, they will not have enough power to over fit the data. Various networks with different number of neurons in their hidden layers were trained with ML algorithms. Ultimately, three networks with Logsig-Logsig-purelin activation function and 6-7-6-1 neuron in input-first hidden layer-second hidden layer-output were suitable for this application by which the mean square errors for all testing data for all three networks were 0.025 .

\section{A. Reactive power compensation}

Testing result for each network for 60 unbalanced conditions is shown in Table.2. For each unbalanced condition both real and imag parts of three phase current as mentioned before were used. And at the right side of the table both desired and actual firing angle for compensate reactive power during load fluctuation is come. The amount of reactive power which is supplied by the system $(Q s)$ with out compensation and with compensation (ANN-based FC-TCR) for all 60 cases in Table.2, are shown in Fig.3.

\section{B. Balancing three phase currents}

The three phase currents which are supplied by the system (Ias, Ibs and Ics) also balanced by this purposed scheme. The amount of three phase currents for all 60 cases in Table. 2 after power reactive compensation and balancing system are shown in Fig.4. Also unbalanced factor for all 60 cases before and after compensation is shown in Table. 3 .

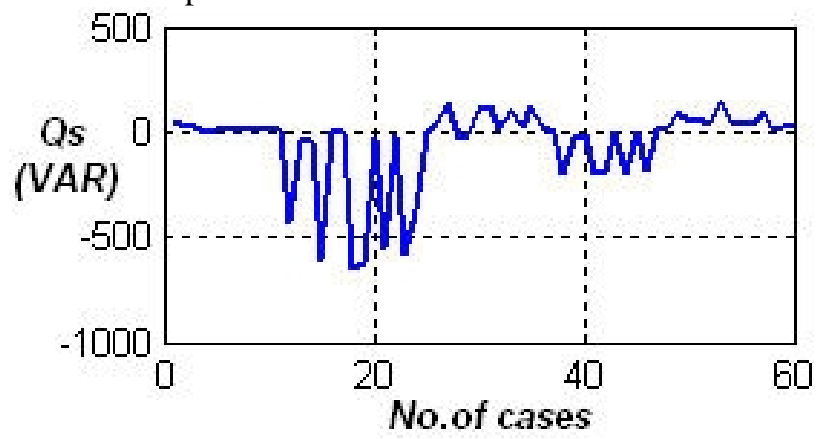

(a)

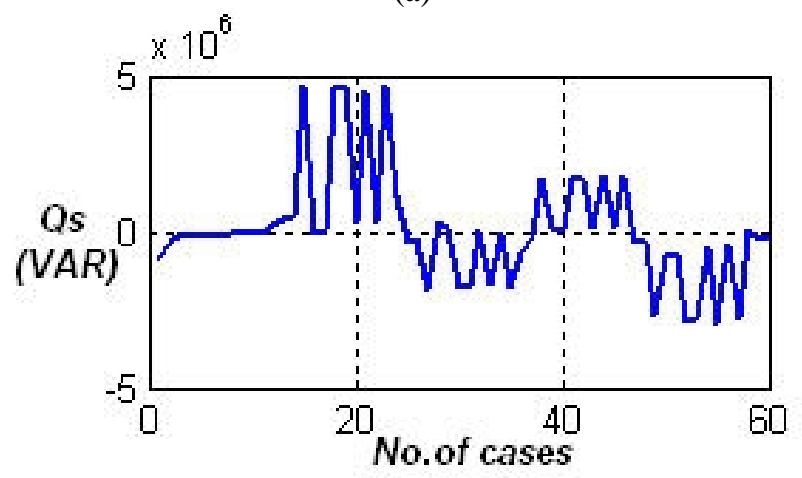

(b)

Fig. 2 (a) Qs Supplied by the system with out compensation (b) Qs Supplied by the system with ANN based FC-TCR compensation 


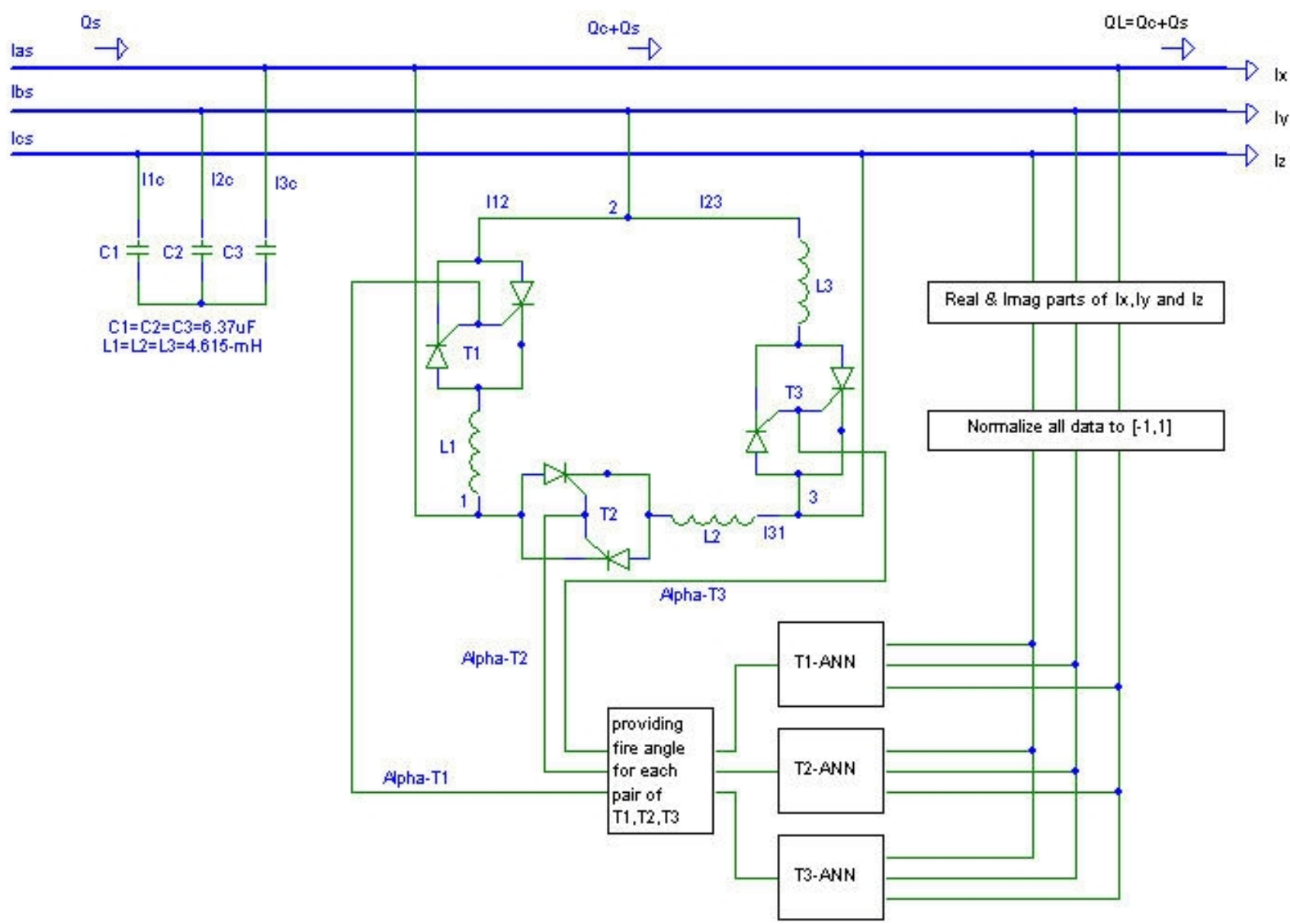

Fig. 3 Load compensator modeling using (TCR) \&FC combined with ANN
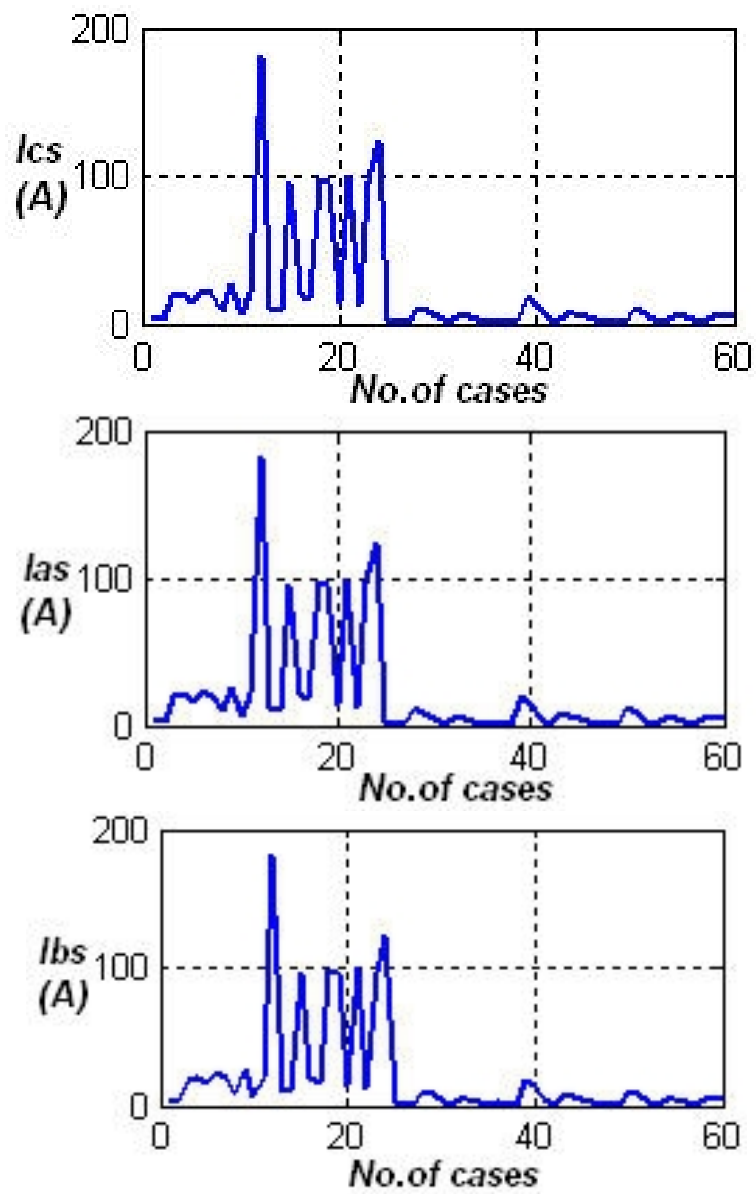

Fig. 4 Three phase current after power reactive compensation by ANN based FC-TCR for all 60 cases in Table .2

\section{CONCLUSION}

A medium voltage system $33 \mathrm{KV}$ is selected for this study and ANN based FC-TCR compensator is considered. ANN capabilities in pattern recognition and classification are designed. Simulation studies are performed and module's performance with different system conditions is investigated. It was found that ANN application is very accurate and useful for control of reactive power and balancing system.

- From the study Table.2. It can be seen that ANN is very quick and reliable to find appropriate firing angle for thyristors which are concerning to compensate any unbalanced condition in the system.

- Control of reactive and minimizing the reactive power drawn from the supply. Fig.3. (a) and (b), shows by selecting appropriate firing angle for Thyristors amount of reactive power drawn from the supply is minimized significantly so that power factor also is corrected.

Balancing three phase currents and minimizing the unbalanced factor, from the Table.3. and Fig.4. It can be observed that this proposed algorithm is able to balance three phase current and minimize the unbalanced factor $\left(\boldsymbol{I}_{\text {Negative-sequence }} / \boldsymbol{I}_{\text {positive-sequence }}\right)$ in any unbalanced condition. 
TABLE. II: DESIRED AND ACTUAL FIRING ANGLE OF T1, T2 AND T3 FOR ANN-BASED FC-TCR TO COMPENSATE REACTIVE POWER AND BALANCE SEVERAL UNBALANCED CONDITIONS

\begin{tabular}{|c|c|c|c|c|c|c|c|c|c|c|c|}
\hline \multirow[t]{2}{*}{ Real $\left(I_{a)}\right.$} & \multirow{2}{*}{$\begin{array}{l}\mathbf{I m} \\
\left(\mathbf{I}_{\mathrm{a})}\right.\end{array}$} & \multirow{2}{*}{$\begin{array}{c}\text { Real } \\
\left(\mathbf{I}_{\mathbf{b})}\right.\end{array}$} & \multirow{2}{*}{$\begin{array}{l}\mathbf{I m} \\
\left(\mathbf{I}_{\mathbf{b})}\right.\end{array}$} & \multirow{2}{*}{$\begin{array}{c}\text { Real } \\
\left(\mathbf{I}_{\mathbf{c}}\right)\end{array}$} & \multirow{2}{*}{$\begin{array}{l}\text { Im } \\
\left(\mathbf{I}_{\mathbf{c}}\right)\end{array}$} & \multicolumn{3}{|c|}{ Desired fire angle (Angle) } & \multicolumn{3}{|c|}{ ANN fire angle (Angle) } \\
\hline & & & & & & $\alpha_{\mathrm{T} 1}$ & $\alpha_{\mathrm{T} 2}$ & $\boldsymbol{\alpha}_{\mathrm{T} 3}$ & $\alpha_{T 1}$ & $\alpha_{\mathrm{T} 2}$ & $\alpha_{\mathrm{T} 3}$ \\
\hline 9.4792 & 46.36 & -10.65 & 28.28 & 15.074 & 19.888 & 158.05 & 148.88 & 179.29 & 158.1 & 148.88 & 176.76 \\
\hline 2.2872 & 15.761 & -2.3191 & 8.0488 & 6.6639 & 7.9163 & 156.88 & 147.66 & 156.79 & 156.87 & 147.66 & 156.8 \\
\hline 0.86958 & 6.7846 & 26.281 & -12.385 & 30.176 & 19.206 & 132.12 & 147.53 & 178.69 & 132.09 & 147.53 & 176.71 \\
\hline 28.259 & 1.7528 & 16.7 & 7.2926 & 17.683 & -5.4883 & 156.42 & 147.54 & 139.33 & 156.42 & 147.54 & 139.32 \\
\hline 19.916 & 11.255 & 10.989 & 10.666 & 15.963 & 3.2289 & 157.58 & 149.5 & 150.36 & 157.57 & 149.5 & 150.36 \\
\hline 7.4994 & 10.721 & 29.168 & -7.3665 & 33.998 & 20.442 & 135.66 & 149.29 & 178.03 & 135.64 & 149.29 & 176.25 \\
\hline 2.2415 & 6.0672 & 27.478 & -12.103 & 30.596 & 18.837 & 132.09 & 148.01 & 175.32 & 132.07 & 148.01 & 175.64 \\
\hline 11.391 & 0.28394 & 8.5054 & 1.7631 & 8.6675 & -1.4758 & 150.15 & 147.5 & 145.22 & 150.15 & 147.5 & 145.23 \\
\hline 10.466 & 2.5268 & 33.441 & -12.228 & 34.731 & 15.045 & 132.14 & 147.72 & 160.85 & 132.12 & 147.72 & 160.84 \\
\hline 7.1755 & 4.7604 & 5.6047 & 3.2983 & 7.6567 & 2.6689 & 151.48 & 148.42 & 150.59 & 151.48 & 148.42 & 150.59 \\
\hline 3.2673 & 4.4171 & 28.949 & -12.682 & 30.916 & 18.108 & 131.54 & 148.27 & 169.53 & 131.52 & 148.27 & 169.57 \\
\hline 154.67 & 100.17 & 199.48 & 83.457 & 191.56 & 130.61 & 158.32 & 128.33 & 120.15 & 158.08 & 128.09 & 120.41 \\
\hline 4.6025 & 11.449 & 21.186 & 16.628 & 8.4097 & 28.399 & 147.25 & 165.78 & 158.32 & 147.25 & 165.81 & 158.31 \\
\hline 10.765 & -1.8206 & 16.293 & 11.315 & 2.1542 & 9.5336 & 147.47 & 158.23 & 144.72 & 147.47 & 158.23 & 144.73 \\
\hline 141.34 & -79.761 & 143.71 & 83.846 & 0.84437 & 4.0854 & 147.5 & 115.05 & 101.43 & 147.49 & 115.04 & 101.53 \\
\hline 27.883 & 1.0196 & 17.194 & 6.6876 & 17.631 & -5.4041 & 155.87 & 147.7 & 139.3 & 155.87 & 147.7 & 139.3 \\
\hline 19.474 & 3.889 & 17.366 & 7.5233 & 15.273 & 3.8792 & 152.9 & 152.89 & 147.69 & 152.9 & 152.89 & 147.69 \\
\hline 142.19 & -75.834 & 145.29 & 83.014 & 6.1775 & 6.2751 & 148.19 & 115.62 & 102.68 & 148.19 & 115.62 & 102.86 \\
\hline 141.87 & -79.582 & 144.06 & 83.309 & 1.9045 & 3.752 & 147.48 & 115.28 & 101.5 & 147.48 & 115.27 & 101.6 \\
\hline 19.901 & -4.7815 & 15.44 & 7.6043 & 6.9447 & -2.4522 & 151.4 & 154.32 & 136.93 & 151.4 & 154.32 & 136.92 \\
\hline 147.23 & -77.897 & 144.1 & 81.989 & 7.201 & -0.6685 & 151.04 & 117.02 & 101.26 & 151.02 & 117.05 & 101.33 \\
\hline 15.806 & -3.5845 & 15.512 & 8.0305 & 5.6005 & 1.9675 & 149.38 & 156.06 & 140.27 & 149.38 & 156.06 & 140.27 \\
\hline 142.67 & -79.669 & 143.89 & 82.681 & 2.6827 & 2.5587 & 147.85 & 115.67 & 101.38 & 147.84 & 115.67 & 101.47 \\
\hline 170.39 & 155.66 & 116.98 & 226.35 & 82.47 & 144.74 & 101.17 & 105.43 & 149.14 & 101.11 & 107.05 & 149.01 \\
\hline 13.666 & 36.188 & -6.612 & 38.307 & 1.6937 & 19.687 & 158.04 & 158.1 & 157.33 & 158.1 & 158.1 & 157.34 \\
\hline 0.31108 & 18.859 & -3.174 & 12.763 & 3.8483 & 12.794 & 157.6 & 152.36 & 157.61 & 157.6 & 152.36 & 157.61 \\
\hline-52.583 & 99.311 & -1.4808 & 5.457 & 54.248 & 96.643 & 153.27 & 149.61 & 110.61 & 153.28 & 149.61 & 110.6 \\
\hline 9.165 & 2.0098 & 16.747 & 7.3797 & 8.3059 & 11.261 & 146.06 & 157.09 & 151.82 & 146.06 & 157.09 & 151.82 \\
\hline 9.2313 & 8.6421 & 11.207 & 11.589 & 7.6679 & 11.827 & 153.44 & 156.51 & 153.72 & 153.44 & 156.51 & 153.72 \\
\hline-46.794 & 99.319 & 2.9882 & 9.6432 & 55.759 & 97.597 & 155.07 & 153.14 & 111.22 & 155.08 & 153.13 & 111.13 \\
\hline-51.741 & 98.415 & 0.0679 & 5.2016 & 54.889 & 96.679 & 152.52 & 150.11 & 110.73 & 152.53 & 150.11 & 110.7 \\
\hline 0.27945 & 6.342 & 6.7984 & 2.7669 & 6.6352 & 10.2 & 146.66 & 152.31 & 156.14 & 146.66 & 152.31 & 156.15 \\
\hline-48.868 & 93.189 & 6.0663 & 3.757 & 56.05 & 96.05 & 148.19 & 152.31 & 111.55 & 148.19 & 152.3 & 111.48 \\
\hline 0.15865 & 9.6215 & 3.9692 & 4.7283 & 6.3017 & 10.475 & 150.41 & 151.61 & 156.71 & 150.41 & 151.61 & 156.72 \\
\hline-51.507 & 96.851 & 1.3654 & 3.9944 & 55.346 & 96.214 & 150.95 & 150.03 & 110.88 & 150.95 & 150.03 & 110.85 \\
\hline 9.4792 & 46.36 & -10.758 & 34.693 & 9.4661 & 23.002 & 157.46 & 155.06 & 168.15 & 157.45 & 155.05 & 167.84 \\
\hline 2.2872 & 15.761 & -2.427 & 14.462 & 1.0561 & 11.03 & 157.67 & 154.21 & 155.53 & 157.67 & 154.21 & 155.53 \\
\hline 0.86958 & 6.7846 & 25.202 & 51.748 & -25.902 & 50.338 & 153.31 & 134.62 & 151.47 & 153.31 & 134.63 & 151.46 \\
\hline 28.259 & 1.7528 & 16.592 & 13.706 & 12.075 & -2.375 & 157.39 & 154.12 & 137.23 & 157.38 & 154.12 & 137.22 \\
\hline 19.916 & 11.255 & 10.881 & 17.079 & 10.356 & 6.3421 & 158.13 & 155.45 & 147.9 & 158.14 & 155.45 & 147.9 \\
\hline 7.4994 & 10.721 & 28.089 & 56.766 & -22.08 & 51.574 & 156.88 & 133.53 & 151.57 & 156.87 & 133.56 & 151.57 \\
\hline 2.2415 & 6.0672 & 26.399 & 52.029 & -25.482 & 49.969 & 153.27 & 134.31 & 150.5 & 153.27 & 134.33 & 150.5 \\
\hline 11.391 & 0.28394 & 8.3975 & 8.1764 & 3.0597 & 1.6374 & 152.44 & 154.1 & 142.71 & 152.45 & 154.1 & 142.72 \\
\hline 10.466 & 2.5268 & 32.362 & 51.905 & -21.347 & 46.177 & 153.35 & 134.49 & 145.03 & 153.35 & 134.51 & 145.04 \\
\hline 7.1755 & 4.7604 & 5.4968 & 9.7115 & 2.0489 & 5.782 & 153.61 & 154.75 & 148.14 & 153.62 & 154.75 & 148.14 \\
\hline 3.2673 & 4.4171 & 27.871 & 51.45 & -25.162 & 49.24 & 152.32 & 134.15 & 149.18 & 152.32 & 134.16 & 149.18 \\
\hline-1.4367 & 33.987 & -1.3542 & 22.666 & 8.4097 & 28.399 & 159.82 & 157.21 & 173.45 & 159.8 & 157.2 & 173.75 \\
\hline 4.7261 & 20.718 & -6.2469 & 17.354 & 2.1542 & 9.5336 & 159.98 & 152.01 & 155.78 & 159.95 & 152.01 & 155.78 \\
\hline 80.952 & 145.63 & -81.687 & 144.24 & 0.84437 & 4.0854 & 92.55 & 149.54 & 151.54 & 92.535 & 149.54 & 151.53 \\
\hline 21.844 & 23.558 & -5.3457 & 12.727 & 17.631 & -5.404 & 167.8 & 136.13 & 151.51 & 167.06 & 136.13 & 151.5 \\
\hline 13.435 & 26.428 & -5.1744 & 13.562 & 15.273 & 3.8792 & 172.19 & 140.73 & 157.12 & 172.8 & 140.73 & 157.12 \\
\hline 81.793 & 149.55 & -80.105 & 143.4 & 6.1775 & 6.2751 & 92.459 & 147.6 & 155.57 & 92.467 & 147.59 & 155.58 \\
\hline 81.481 & 145.81 & -81.336 & 143.7 & 1.9045 & 3.752 & 92.552 & 148.75 & 151.8 & 92.537 & 148.76 & 151.79 \\
\hline 13.861 & 17.757 & -7.0996 & 13.643 & 6.9447 & -2.4522 & 166.33 & 142.48 & 148.77 & 166.2 & 142.48 & 148.77 \\
\hline 86.833 & 147.49 & -81.3 & 142.38 & 7.201 & -0.6685 & 92.098 & 143.07 & 150.81 & 92.246 & 143.05 & 150.81 \\
\hline 9.7668 & 18.954 & -7.0281 & 14.069 & 5.6005 & 1.9675 & 162.03 & 145.25 & 152.46 & 162.05 & 145.25 & 152.46 \\
\hline 82.273 & 145.72 & -81.51 & 143.07 & 2.6827 & 2.5587 & 92.504 & 147.43 & 151.35 & 92.499 & 147.43 & 151.34 \\
\hline-1.0968 & 15.453 & 7.2799 & 12.416 & 5.7213 & 21.189 & 152.35 & 157.46 & 158.5 & 152.35 & 157.46 & 158.48 \\
\hline 6.3654 & 11.579 & 2.0956 & 5.043 & 9.8917 & 4.6136 & 155.38 & 146.02 & 154.96 & 155.38 & 146.02 & 154.96 \\
\hline 7.2547 & 6.1559 & 2.4033 & 3.9627 & 6.7287 & 0.85789 & 153.94 & 146.47 & 149.8 & 153.95 & 146.47 & 149.8 \\
\hline
\end{tabular}

TABLE III: COMPARISON OF UNBALANCED FACTOR BEFORE AND AFTER COMPENSATION BY ANN-BASED FC-TCR FOR ALL 60 CASES IN TABLE. 2 


\begin{tabular}{|c|c|c|c|c|c|}
\hline $\begin{array}{c}\text { of } \\
\text { Cases }\end{array}$ & $\alpha_{\mathrm{T} 1}$ & $\boldsymbol{\alpha}_{\mathrm{T} 2}$ & $\boldsymbol{\alpha}_{\mathbf{T} 3}$ & Before compensation by ANN & After compensation by ANN \\
\hline 1 & 158.1 & 148.88 & 176.76 & $0.48349+0.082628 \mathrm{i}$ & $-5.8841 \mathrm{e}-005+0.00020071 \mathrm{i}$ \\
\hline 2 & 156.87 & 147.66 & 156.8 & $0.47131-0.091306 \mathrm{i}$ & $0.00033608+0.00023485 \mathrm{i}$ \\
\hline 3 & 132.09 & 147.53 & 176.71 & $-0.87715-0.32591 \mathrm{i}$ & $0.00012208+2.8492 \mathrm{e}-005 \mathrm{i}$ \\
\hline 4 & 156.42 & 147.54 & 139.32 & $0.35379-0.0071042 \mathrm{i}$ & $1.7023 \mathrm{e}-005-7.1541 \mathrm{e}-006 \mathrm{i}$ \\
\hline 5 & 157.57 & 149.5 & 150.36 & $0.28998-0.02824 \mathrm{i}$ & $2.8042 \mathrm{e}-005+1.9746 \mathrm{e}-005 \mathrm{i}$ \\
\hline 6 & 135.64 & 149.29 & 176.25 & $-0.57638-0.31252 \mathrm{i}$ & $8.5554 \mathrm{e}-005+1.0244 \mathrm{e}-005 \mathrm{i}$ \\
\hline 7 & 132.07 & 148.01 & 175.64 & $-0.83202-0.26615 i$ & $0.00010975+7.2112 \mathrm{e}-006 \mathrm{i}$ \\
\hline 8 & 150.15 & 147.5 & 145.23 & $0.19652-0.0059212 \mathrm{i}$ & $8.7089 \mathrm{e}-005+3.0776 \mathrm{e}-005 \mathrm{i}$ \\
\hline 9 & 132.12 & 147.72 & 160.84 & $-0.59603-0.068953 \mathrm{i}$ & $8.1494 \mathrm{e}-005+1.2133 \mathrm{e}-005 \mathrm{i}$ \\
\hline 10 & 151.48 & 148.42 & 150.59 & $0.11339-0.11441 \mathrm{i}$ & $0.00012607+5.2621 \mathrm{e}-005 \mathrm{i}$ \\
\hline 11 & 131.52 & 148.27 & 169.57 & $-0.81648-0.1813 \mathrm{i}$ & $0.00011268+1.4275 \mathrm{e}-005 \mathrm{i}$ \\
\hline 12 & 158.08 & 128.09 & 120.41 & $-0.12327-0.045872 \mathrm{i}$ & $-1.0158 \mathrm{e}-005-4.1703 \mathrm{e}-005 i$ \\
\hline 13 & 147.25 & 165.81 & 158.31 & $-0.44666-0.090579 \mathrm{i}$ & $6.0334 \mathrm{e}-005-6.2883 \mathrm{e}-005 \mathrm{i}$ \\
\hline 14 & 147.47 & 158.23 & 144.73 & $-0.30924+0.63686 \mathrm{i}$ & $4.4211 \mathrm{e}-005-7.3697 \mathrm{e}-005 \mathrm{i}$ \\
\hline 15 & 147.49 & 115.04 & 101.53 & $0.45808+0.87858 \mathrm{i}$ & $-5.2027 \mathrm{e}-005-0.00011223 \mathrm{i}$ \\
\hline 16 & 155.87 & 147.7 & 139.3 & $0.33397+0.00018064 \mathrm{i}$ & $1.6732 \mathrm{e}-005-7.6048 \mathrm{e}-006 \mathrm{i}$ \\
\hline 17 & 152.9 & 152.89 & 147.69 & $0.092713+0.096732 \mathrm{i}$ & $2.7741 \mathrm{e}-005+2.0062 \mathrm{e}-006 \mathrm{i}$ \\
\hline 18 & 148.19 & 115.62 & 102.86 & $0.41417+0.83945 \mathrm{i}$ & $-1.4359 \mathrm{e}-005-0.00011531 \mathrm{i}$ \\
\hline 19 & 147.48 & 115.27 & 101.6 & $0.45618+0.86723 \mathrm{i}$ & $-4.7059 \mathrm{e}-005-0.00011392 \mathrm{i}$ \\
\hline 20 & 151.4 & 154.32 & 136.92 & $0.40884+0.35153 \mathrm{i}$ & $4.105 \mathrm{e}-005-3.0514 \mathrm{e}-005 \mathrm{i}$ \\
\hline 21 & 151.02 & 117.05 & 101.33 & $0.4704+0.79962 \mathrm{i}$ & $-2.3696 e-005-9.7385 e-005 i$ \\
\hline 22 & 149.38 & 156.06 & 140.27 & $0.19769+0.49931 \mathrm{i}$ & $4.2534 \mathrm{e}-005-2.6399 \mathrm{e}-005 \mathrm{i}$ \\
\hline 23 & 147.84 & 115.67 & 101.47 & $0.46333+0.85445 i$ & $-2.4928 \mathrm{e}-005-0.00010423 \mathrm{i}$ \\
\hline 24 & 101.11 & 107.05 & 149.01 & $0.050201+0.23306 \mathrm{i}$ & $-7.1627 e-005-5.3889 e-005 i$ \\
\hline 25 & 158.1 & 158.1 & 157.34 & $0.18296+0.3254 \mathrm{i}$ & $-0.00023525-1.8856 \mathrm{e}-005 \mathrm{i}$ \\
\hline 26 & 157.6 & 152.36 & 157.61 & $0.27366-0.0072971 \mathrm{i}$ & $0.0022917+0.0017958 \mathrm{i}$ \\
\hline 27 & 153.28 & 149.61 & 110.6 & $0.47855-0.7846 \mathrm{i}$ & $0.06654+0.037667 \mathrm{i}$ \\
\hline 28 & 146.06 & 157.09 & 151.82 & $-0.33302+0.22627 i$ & $9.4001 \mathrm{e}-005-3.833 \mathrm{e}-005 \mathrm{i}$ \\
\hline 29 & 153.44 & 156.51 & 153.72 & $-0.11449+0.087503 \mathrm{i}$ & $8.8795 \mathrm{e}-005-3.823 \mathrm{e}-005 \mathrm{i}$ \\
\hline 30 & 155.08 & 153.13 & 111.13 & $0.39851-0.76058 \mathrm{i}$ & $0.00094954+0.00046875 i$ \\
\hline 31 & 152.53 & 150.11 & 110.7 & $0.46127-0.79846 \mathrm{i}$ & $0.0035897+0.0019921 \mathrm{i}$ \\
\hline 32 & 146.66 & 152.31 & 156.15 & $-0.32449-0.43634 \mathrm{i}$ & $0.00025069+6.5928 \mathrm{e}-005 \mathrm{i}$ \\
\hline 33 & 148.19 & 152.3 & 111.48 & $0.38991-0.85506 i$ & $0.00087236+0.0004214 i$ \\
\hline 34 & 150.41 & 151.61 & 156.72 & $-0.0048407-0.39894 i$ & $0.00029963+0.00012494 i$ \\
\hline 35 & 150.95 & 150.03 & 110.85 & $0.45276-0.82253 \mathrm{i}$ & $0.0021555+0.0012124 \mathrm{i}$ \\
\hline 36 & 157.45 & 155.05 & 167.84 & $0.34978+0.16706 \mathrm{i}$ & $-7.5698 \mathrm{e}-005+0.00016962 \mathrm{i}$ \\
\hline 37 & 157.67 & 154.21 & 155.53 & $0.14935+0.14076 \mathrm{i}$ & $0.0020669+0.00023622 \mathrm{i}$ \\
\hline 38 & 153.31 & 134.63 & 151.46 & $-0.813+0.023668 \mathrm{i}$ & $-0.010024-0.057724 \mathrm{i}$ \\
\hline 39 & 157.38 & 154.12 & 137.22 & $0.43472+0.23734 \mathrm{i}$ & $4.8329 \mathrm{e}-006-2.7463 \mathrm{e}-005 \mathrm{i}$ \\
\hline 40 & 158.14 & 155.45 & 147.9 & $0.25337+0.23557 \mathrm{i}$ & $8.9823 \mathrm{e}-006-2.0795 \mathrm{e}-005 \mathrm{i}$ \\
\hline 41 & 156.87 & 133.56 & 151.57 & $-0.71211+0.1563 i$ & $-0.00015336-0.00078043 i$ \\
\hline 42 & 153.27 & 134.33 & 150.5 & $-0.82988+0.057249 \mathrm{i}$ & $-0.00033914-0.0033491 i$ \\
\hline 43 & 152.45 & 154.1 & 142.72 & $0.26508+0.52177 \mathrm{i}$ & $7.148 \mathrm{e}-005-1.1942 \mathrm{e}-005 \mathrm{i}$ \\
\hline 44 & 153.35 & 134.51 & 145.04 & $-0.86419+0.2831 \mathrm{i}$ & $-9.9638 \mathrm{e}-005-0.00049174 \mathrm{i}$ \\
\hline 45 & 153.62 & 154.75 & 148.14 & $-0.033119+0.36008 \mathrm{i}$ & $0.00011699+1.5952 \mathrm{e}-006 \mathrm{i}$ \\
\hline 46 & 152.32 & 134.16 & 149.18 & $-0.86905+0.085808 \mathrm{i}$ & $-0.00017937-0.0015475 i$ \\
\hline 47 & 159.8 & 157.2 & 173.75 & $0.19029-0.12934 \mathrm{i}$ & $0.00035753+0.00012579 i$ \\
\hline 48 & 159.95 & 152.01 & 155.78 & $0.30937+0.28038 \mathrm{i}$ & $0.00080593+0.0016856 \mathrm{i}$ \\
\hline 49 & 92.535 & 149.54 & 151.53 & $0.48659+0.82558 \mathrm{i}$ & $-0.22254+0.068836 \mathrm{i}$ \\
\hline 50 & 167.06 & 136.13 & 151.5 & $1.086-0.18335 \mathrm{i}$ & $-7.8538 \mathrm{e}-006+7.3606 \mathrm{e}-005 \mathrm{i}$ \\
\hline 51 & 172.8 & 140.73 & 157.12 & $0.78615-0.039442 \mathrm{i}$ & $4.6078 \mathrm{e}-005+0.00014608 \mathrm{i}$ \\
\hline 52 & 92.467 & 147.59 & 155.58 & $0.51992+0.78004 i$ & $-0.0023447+0.00022819 \mathrm{i}$ \\
\hline 53 & 92.537 & 148.76 & 151.79 & $0.49738+0.82302 \mathrm{i}$ & $-0.011478+0.0037116 \mathrm{i}$ \\
\hline 54 & 166.2 & 142.48 & 148.77 & $1.0589+0.46163 \mathrm{i}$ & $-1.8985 \mathrm{e}-006+0.00016308 \mathrm{i}$ \\
\hline 55 & 92.246 & 143.05 & 150.81 & $0.56664+0.83172 \mathrm{i}$ & $-0.0018166+0.00021553 i$ \\
\hline 56 & 162.05 & 145.25 & 152.46 & $0.72659+0.42584 \mathrm{i}$ & $0.00012364+0.00026607 \mathrm{i}$ \\
\hline 57 & 92.499 & 147.43 & 151.34 & $0.51032+0.82925 \mathrm{i}$ & $-0.0062414+0.0013709 \mathrm{i}$ \\
\hline 58 & 152.35 & 157.46 & 158.48 & $-0.12293-0.27993 i$ & $0.00026537+5.6398 \mathrm{e}-005 \mathrm{i}$ \\
\hline 59 & 155.38 & 146.02 & 154.96 & $0.38132-0.29454 i$ & $0.00013397+7.3042 \mathrm{e}-005 \mathrm{i}$ \\
\hline 60 & 153.95 & 146.47 & 149.8 & $0.43792-0.16386 \mathrm{i}$ & $0.00014256+9.4868 \mathrm{e}-005 \mathrm{i}$ \\
\hline
\end{tabular}

\section{REFERENCES}

[1] D.Thukaram, A.Lomi and S.Chirarattananon, Minimization of harmonics under three-phase unbalanced operation of static VAR compensators, Proceedings of the 12th International Conference on Power Quality (Power Quality '99), Chicago, USA, 1999.

[2] S.Y.Lee, C.J.Wu and W.N. Chang, A compact control algorithm for reactive power compensation and load balancing with static var compensator, Electric Power Systems Research, 58, 2001, pp.63-70.

[3] G.El-Saady, Adaptive static VAR controller for simultaneous elimination of voltage flicker and phase current imbalances due to arc pp.133-140.

[4] G.Gueth, P.Enstedt, A Ray and R.W.Menzies, Individual phase control of static compensator for load compensation and voltage balancing and regulation, IEEE Trans, Power system, 2(4), 1987, pp.898-904

[5] A. Rajapakse and Anawat Puangpairoj, Harmonic reducing ANN controller for a SVS compensating unbalanced fluctuating loads, International Journal of Emerging Electric Power Systems, 7 (1), 2006, Article 5.

[6] R.Mohan Mathur and Rajiv K.Varma, Thyristor-based FACTs controllers for electrical transmission systems, John Wiley \& sons publications, 2002 pp.63-71. 
[7] Jayabarathi.R.a and Devarajan.N.b, ANN based DSPIC controller for reactive power compensation, American journal of applied science, 4(7), 2007, pp.508-515

[8] Hagan, M.T and M.Menhaj, Training feed forward networks with the Marquardt algorithm, IEEE. Transaction on Neural Networks, 5(6), 1999, pp.989-993

[9] Muhammad H. Rashid, Power electronics circuits, devices and application, Second Edition, Prentice-Hall, 1993.

[10] Brian D. Hahn and Daniel T. Valentine, Essential MATLAB for Engineers and Scientists, Third edition, Published by Elsevier, 2002.

Ismail K. Said, is graduated from Salahaddin University both BSc and MSc and now he is assistant lecturer at the Electrical Department, his area of interest is control of power system

Marouf Pirouti is graduated BSc from K.N.T University of Technology Tehran-Iran, 2003 and MSc from Salahaddin University, 2007. He is now assistant lecturer at Electrical Department of Salahaddin University and also he is teaching at the Dejleh College .His area of interest is control of power and application of $\mathrm{AI}$ in power system. 